\title{
Dexmedetomidine combined with sufentanil and dezocine-based patient- controlled intravenous analgesia increases female patients' global satisfaction degree after thoracoscopic surgery
}

\author{
Qiongzhen $\mathrm{Li}^{\dagger}$, Haixia $\mathrm{Yao}^{\dagger}$, Meiying Xu and Jingxiang $\mathrm{Wu}^{*}$ (D)
}

\begin{abstract}
Background: There are no studies on the use of dexmedetomidine combined with sufentanil and dezocine-based patient-controlled intravenous analgesia (PCIA) in females undergoing thoracic surgery. We postulate that introducing dexmedetomidine to a combination of dezocine-based PCA drugs and sufentanil will increase female patients' global satisfaction degree.

Methods: One hundred fifty-two female patients with physical classification type I or II according to the American Society of Anesthesiologists undergoing thoracoscopic surgery were arbitrarily classified into two categories, either receiving sufentanil and dezocine-based PCIA (group C) or incorporating dexmedetomidine with sufentanil and dezocine-based PCIA (group D). The patients' global satisfaction degree, postoperative nausea and vomiting (PONV), PCA bolus, rescue analgesia requirements, drug-related adverse effects, rest and coughing visual analogue scale (VAS) ratings, and Ramsay sedation scores (RSS) were measured at 6, 12, 24, 36 and $48 \mathrm{~h}$ after surgery.

Results: Compared with the $C$ group, the patient satisfaction degree was significantly higher; pain scores at rest and coughing were significantly different at $6,12,24,36$ and $48 \mathrm{~h}$ postoperatively; less rescue analgesia and PCA bolus were required; and a lower incidence of PONV was found in the D group. There were non-significant trends for the sedation scores and drug-related adverse effects in both groups.

Conclusions: Dexmedetomidine combined with sufentanil and dezocine increased female patients' global satisfaction degree after thoracoscopic surgery. This effect could be linked to the improvement in postoperative analgesia and reduction in postoperative nausea and vomiting; the combined treatment did not increase drugrelated adverse effects in female patients.
\end{abstract}

Trial registration: Chinese Clinical Trial Registry number, ChiCTR2000030429. Registered on March 1, 2020. Keywords: Satisfaction degree, Sufentanil, Dexmedetomidine, Dezocine, Combination, Thoracoscopic, PatientControlled Intravenous Analgesia.

\footnotetext{
* Correspondence: Wu jingxiang@shchest.org

${ }^{\dagger}$ Qiongzhen Li and Haixia Yao contributed equally to this work.

Department of Anesthesiology of Shanghai Chest Hospital, Shanghai

Jiaotong University, No. 241 Huaihai Rd. West, Shanghai 200025, China
}

(c) The Author(s). 2021 Open Access This article is licensed under a Creative Commons Attribution 4.0 International License, which permits use, sharing, adaptation, distribution and reproduction in any medium or format, as long as you give appropriate credit to the original author(s) and the source, provide a link to the Creative Commons licence, and indicate if changes were made. The images or other third party material in this article are included in the article's Creative Commons licence, unless indicated otherwise in a credit line to the material. If material is not included in the article's Creative Commons licence and your intended use is not permitted by statutory regulation or exceeds the permitted use, you will need to obtain permission directly from the copyright holder. To view a copy of this licence, visit http://creativecommons.org/licenses/by/4.0/. The Creative Commons Public Domain Dedication waiver (http://creativecommons.org/publicdomain/zero/1.0/) applies to the data made available in this article, unless otherwise stated in a credit line to the data. 


\section{Introduction}

With the emergence of enhanced recovery after surgery (ERAS), adequate pain control has been reported to enhance surgical results leading to decreased morbidity, hospitalisation and convalescence, and it is generally accepted that adequate pain management is a requirement for early postoperative rehabilitation [1]. Patients undergoing thoracic surgery experience serious pain with major effects from respiratory movements during the postoperative period $[2,3]$. The most widely used analgesic approach continues to be patient-controlled intravenous analgesia (PCIA). Opioids are analgesics that are frequently used for PCIA. While increased dosages of opioid pharmaceutical products may improve postoperative pain, undesirable drug-related consequences, including pruritus, vomiting, nausea and respiratory distress, often occur, especially for female patients $[4,5]$.

Dezocine is a serotonin-norepinephrine reuptake inhibitor and functions as a partial $\mu$-receptor agonist and K-receptor antagonist [6]. Small doses of dezocine combined with morphine increase the effectiveness of postoperative analgesia for thoracotomy [7]. Dexmedetomidine is a highly selective $\alpha_{2}$ adrenergic receptor agonist that hypnotic, sedative, analgesic and anxiolytic actions and does not cause respiratory depression. Dexmedetomidine can also increase the analgesic efficacy of opioids [8-13]. However, the mechanisms of the effect of dexmedetomidine when combined with opioids remain unclear.

In this randomised, placebo-controlled, double-blind study, we hypothesised that the addition of dexmedetomidine to sufentanil and dezocine-based PCA drug mixtures would improve female patient satisfaction. The secondary goal was to assess the analgesic potency and undesirable outcomes of dexmedetomidine $48 \mathrm{~h}$ after thoracoscopic surgery.

\section{Methods}

\section{Patients and data collection}

A total of 152 female patients who were $30-60$ years of age, were American Society of Anesthesiologists (ASA) class I-II, and presented for three-trocar video-assisted thoracoscopic surgery from February 24, 2020, to April 2, 2020, were enrolled. The Shanghai Jiaotong University Shanghai Chest Hospital (KS1865) Academic Review Board authorised the research procedure for surgeries involving general anaesthesia. We registered this research at Chictr.org (ChiCTR2000030429). Written informed consent was obtained from all participants.

\section{Inclusion criteria}

The female patients were selected as follows: 1) capacity to comprehend Chinese verbal and written, 2) American Society of Anesthesiologists physical status I to II, 3) age
30 to 60 years, 4) scheduled for three-trocar VATS under general anesthesia, and 5) received $48 \mathrm{~h}$ continual PCIA after surgery.

\section{Exclusion criteria}

The exclusion criteria were as follows: 1) age under 30 or over 60 years, 2) refusal to participate, 3) use of psychiatric medications and alcohol abuse, 4) history of cardiovascular disease, 5) acute or chronic liver or kidney disease, 6) cognitive impairment, and 7) pregnancy or lactation.

\section{Randomisation}

Patients were randomised with a 1:1 equal allocation ratio to sufentanil and dezocine-based PCIA (group C) or combined dexmedetomidine with sufentanil and dezocine-based PCIA (group D). A clinical trial statistician provided randomisation by using random number table. After written informed consent, the anaesthetist began randomisation of the patients using the online database. Later, in the procedure room, the randomised treatment was started.

\section{Blinding}

The patients and the research team were not informed as to whether the patients were assigned to the sufentanil and dezocine-based PCIA group (group C) or the combined dexmedetomidine with sufentanil and dezocine-based PCIA group (group D) until the end of the study. Only the clinical trial statistician and dispensing nurse know the group allocation. The blinding could be disrupted in case of emergency if the patients' health or safety were at risk.

\section{Methods of Anaesthesia}

According to the clinical research center protocol, when the patient arriveed at the anaesthesia preparation room, a peripheral vein was opened using a catheter, and right internal jugular central venous catheterisation was performed. When the participants were released to the operating room, in addition to a normal evaluation via pulse oximetry, non-invasive blood pressure (NIBP) and electrocardiography (ECG), the arterial pressure was assessed using a radial artery catheter in all patients. During surgery, surface electrodes for the bi-spectral index were placed on the front of the patients; BIS was maintained between 40 and 50 . For both groups, a standardised anaesthetic method was used. Induction and upkeep of anaesthesia were the responsibility of the participating anaesthesiologists who were blinded to group assignments. Ten minutes before the induction of anaesthesia, $0.5 \mu \mathrm{g} / \mathrm{kg}$ dexmedetomidine (DEX) was in group $\mathrm{D}$ or normal saline in group $\mathrm{C}$ was added to a $20-\mathrm{ml}$ syringe for administration over $10 \mathrm{~min}$. Anaesthesia was 
subsequently induced at an effect-site concentration (Ce) of $4 \mu \mathrm{g} / \mathrm{ml}$ with sufentanil $(0.5 \mu \mathrm{g} / \mathrm{kg})$, cisatracurium $(0.2 \mathrm{mg} / \mathrm{kg}), 50 \mathrm{mg}$ flurbiprofen, and $2 \%$ propofol using a target-controlled infusion (TCI). The patients were intubated with a DLT in the lateral position, which required no operation. The correct position was confirmed with the use of a fibreoptic bronchoscope (FOB). Throughout the initial two-lung ventilation (TLV) and one-lung ventilation $(\mathrm{OLV})$ cycles, the tidal volume was $7 \mathrm{ml} / \mathrm{kg}$, which maintained $\mathrm{PetCO}_{2}$ at $35-45 \mathrm{mmHg}(\mathrm{I} / \mathrm{E}=1: 2$, $\mathrm{f}=12$ ). Anaesthesia was maintained using cisatracurium $(0.12 \mathrm{mg} / \mathrm{kg} / \mathrm{h})$, remifentanil $(0.1-0.3 \mu \mathrm{g} / \mathrm{kg} / \mathrm{min})$ and $2 \%$ propofol, with Ce at $2-3 \mu \mathrm{g} / \mathrm{ml}$ titrated to maintain BIS between 40 and 50; the mean arterial blood pressures (MAPs) and heart rates (HRs) were 20\% less than the baseline values. The nasopharyngeal temperature was maintained at $\geq 36.5^{\circ} \mathrm{C}$. FOB was used to validate the correct DLT location after the patient was placed in a lateral decubitus position once more. Using 100\% oxygen, anaesthesia induction and OLV were introduced and sustained. At the end of the operation, the inspired concentration of oxygen was decreased by $50 \%$ and the positive end expiratory pressure was increased to 5 $\mathrm{cmH}_{2} \mathrm{O}$ after the lung recruitment manoeuvre. At the end of surgery, intravenous infusion of all anaesthetics were stopped, a palonosetron hydrochloride injection ( $0.25 \mathrm{mg}$ for a single injection) was given to prevent nausea and vomiting, and an electronic infusion pump (FSQ-11 PCA; Inc., JiangSu AIPENG, ED, China) for PCIA was connected. After surgery, patients were transferred to a post anaesthesia care unit (PACU). When fully awake, the patients were transferred to a regular ward and monitored during the whole study period.

\section{Postoperative PCIA strategy}

In the PCIA protocol, the sufentanil and dezocine levels were determined based on body weight in the study timeframe. As per the study design, the PCIA base regimen was $1.5 \mu \mathrm{g} / \mathrm{kg}$ sufentanil and $0.3 \mathrm{mg} / \mathrm{kg}$ dezocine diluted to $100 \mathrm{ml}$ with $0.9 \%$ normal saline. In the D group, in addition to the sufentanil and dezocine, $3.0 \mu \mathrm{g} / \mathrm{kg}$ dexmedetomidine was added to the PCIA pump. The PCIA was set to a background infusion rate of $2 \mathrm{ml} / \mathrm{h}$, lock-out interval of $15 \mathrm{~min}$ and $0.5 \mathrm{ml}$ bolus on demand. All study patients received a $0.5 \mathrm{ml}$ i.v. of PCIA solution while connected to a PCIA pump. The PCIA was set to a continuous background infusion of $0.03 \mu \mathrm{g} / \mathrm{kg} / \mathrm{h}$ sufentanil with a bolus of $0.02 \mu \mathrm{g} / \mathrm{kg}$ sufentanil and allowed a continuous background infusion of $0.06 \mu \mathrm{g} / \mathrm{kg} / \mathrm{h}$ dexmedetomidine with a bolus of $0.03 \mu \mathrm{g} / \mathrm{kg}$ dexmedetomidine. The PCA was used continuously for the first $48 \mathrm{~h}$ postoperatively. If patients complained of extreme discomfort, higher than a VAS level of 5, Once released to the general ward, the physicians advised them to push the
PCA button, and if comfort was not achieved, then the nurse would administer a rescue analgesic of $50 \mathrm{mg}$ flurbiprofen intravenously during the $48 \mathrm{~h}$ study period.

\section{Measurements \\ Primary outcome}

The primary endpoint measures was the satisfaction degree in the two groups within $48 \mathrm{~h}$ after surgery. The satisfaction degree scores were from 1 to 4 ( 4 = very satisfied, $3=$ satisfied, $2=$ moderately satisfied, and $1=$ not satisfied).

\section{Secondary outcomes}

The secondary endpoint measures were postoperative nausea and vomiting (PONV), PCA bolus, requirement for rescue analgesia, drug-related adverse effects, the visual analogue scale (VAS) pain scores at rest and while coughing, and the Ramsay sedation score (RSS) at 6, 12, 24,36 and $48 \mathrm{~h}$ postoperatively. The operative times and the incidences of hypotension, atrial fibrillation and sinus bradycardia.

The nausea and vomiting (PONV) ratings were on a 4-point scale ( $1=$ without nausea and vomiting, $2=$ nausea without vomiting, $3=$ less than twice vomiting, $4=$ extreme vomiting more than twice), and the sedation score was on a 6 -point sedation scale ( $1=$ fully awake; $2=$ cooperative, calm; $3=$ response only to verbal commands; $4=$ vigorous response to light stimulation while asleep; $5=$ sleeping without light reaction; $6=$ unarousable) [14]. The degree of resting and coughing pain from the operation was assessed at $6,12,24,36$ and $48 \mathrm{~h}$. A numerical rating scale from 0 to 10 ( 0 indicates no pain at all and 10 reflects the worst pain known) was used to measure pain severity [8].

The 48-h analgesia pump PCA bolus and rescue analgesia were recorded, and the occurrences of nausea and vomiting, pruritus, hypotension (MAP $<60 \mathrm{mmHg}$ ), sinus bradycardia ( $\mathrm{HR}<60$ beats/min), excessive sedation ( $\mathrm{RSS} \geq 3)$, hypoxaemia $\left(\mathrm{SpO}_{2}<93 \%\right)$, and respiratory depression (respiratory rate $<8 \mathrm{bpm}$ ) were recorded for $48 \mathrm{~h}$ postoperatively.

\section{Statistical analysis}

Quantitative variables are reported as the mean \pm standard deviation. Categorical data are defined in terms of frequencies and fractions. The statistical study was carried out using SPSS version 22 (SPSS, Chicago, IL). The $X^{2}$ test or Fisher's exact test was performed to compare all categorical variables. Continuous variables were tested with the non-parametric Mann-Whitney U test or t-test depending on the distribution of the data. Twosided $p$-values $<0.05$ were considered as statistically significant. The sample size was estimated based on an anticipated $20 \%$ drop in the satisfaction degree ratio for 48 


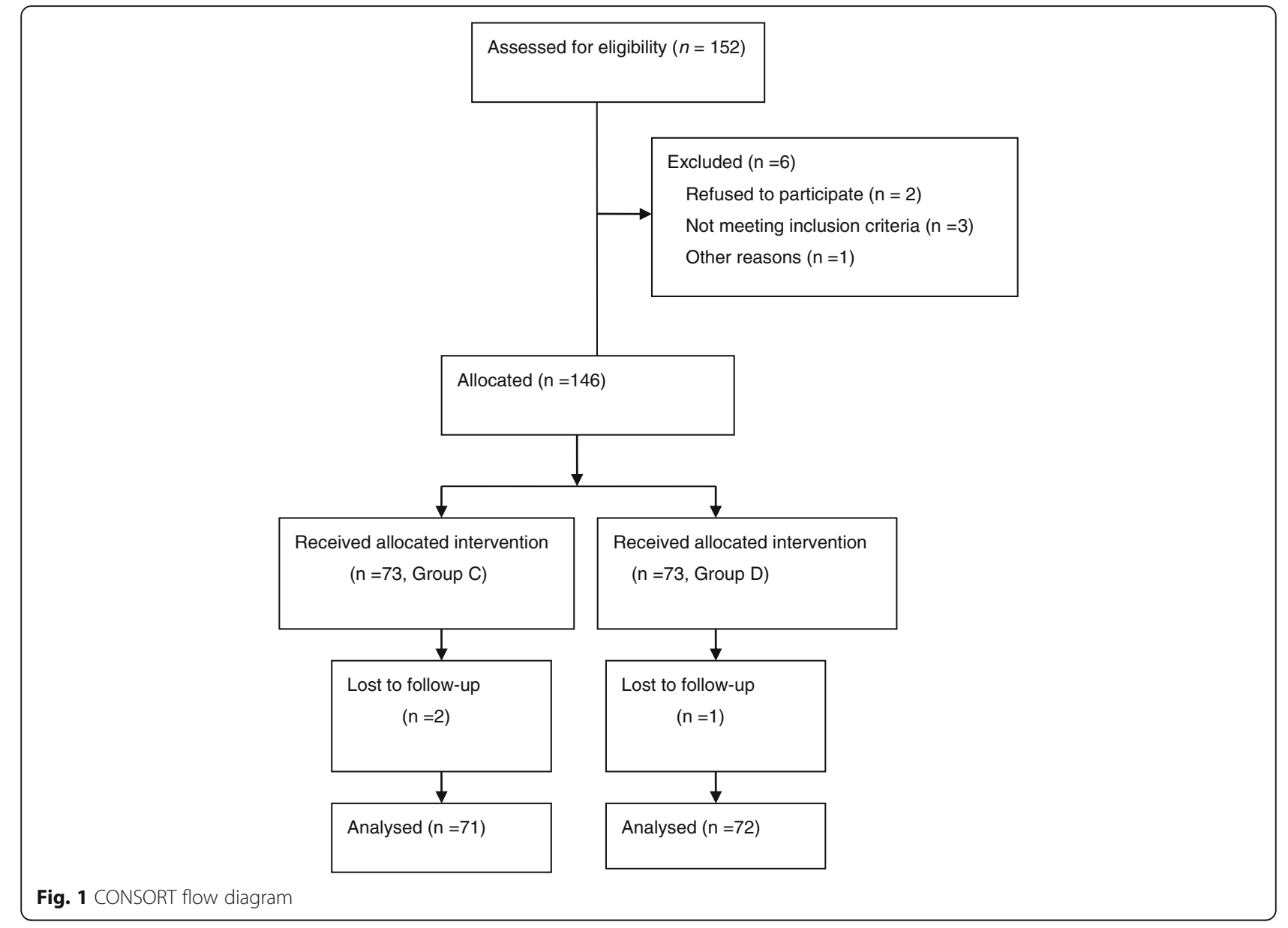

h post-surgery. For an $80 \%$ power $(\alpha=0.05, \beta=0.2)$, the sample size needed for each group was estimated to be 69 , with a dropout rate of $10 \%$. There were 76 patients per group for eligibility.

\section{Results}

A total of 152 female patients were included in this study, but nine were omitted. Eventually, data from 143 patients were entered for final examination (Fig. 1). There were no major variations between the demographic information of the groups (Table 1), namely, height, age, weight, ASA grade, operating period, intraoperative sufentanil and remifentanil intake, or right/left lobectomy resection $(P>0.05$, Table 1$)$.

The patients in group D had a slightly greater degree of satisfaction than the patients in group $\mathrm{C}(p<0.05$, Table 2). Table 3 displays the rescue analgesia and the PCA pump bolus. Post-operative rescue analgesia showed major differences between the groups. The $\mathrm{D}$

Table 1 Patient characteristics

\begin{tabular}{llll}
\hline Variable & Group C $(\boldsymbol{n}=\mathbf{7 1})$ & Group D $(\boldsymbol{n}=\mathbf{7 2})$ & $\mathbf{P}$ values \\
\hline Age (years) & $51.7 \pm 7.9$ & $50.3 \pm 6.90$ & 0.272 \\
Weight $(\mathrm{kg})$ & $58.3 \pm 7.1$ & $57.9 \pm 7.3$ & 0.755 \\
Height $(\mathrm{cm})$ & $160.1 \pm 5.5$ & $159.3 \pm 5.9$ & 0.413 \\
ASA class I/II(n) & $34 / 37$ & $39 / 33$ & 0.505 \\
Time in surgery (min) & $122.8 \pm 7.6$ & $120.4 \pm 7.2$ & 0.063 \\
Intraoperative sufentanil consumption $(\mu \mathrm{g})$ & $29.3 \pm 3.9$ & $29.2 \pm 3.6$ & 0.943 \\
Intraoperative remifentanil consumption $(\mu \mathrm{g})$ & $1406.8 \pm 172.6$ & $1391.0 \pm 174.6$ & 0.588 \\
Right/Left lobectomy resection $(\mathrm{n})$ & $31 / 40$ & $35 / 37$ & 0.616 \\
\hline
\end{tabular}

Data are expressed as the means \pm SD or number 
Table 2 Satisfaction degree within $48 \mathrm{~h}$

\begin{tabular}{llll}
\hline Variable & Group C $(\boldsymbol{n}=\mathbf{7 1})$ & Group D $(\boldsymbol{n}=\mathbf{7 2})$ & $\boldsymbol{P}$ values \\
\hline Not satisfied & $14(19.7 \%)$ & $4(5.5 \%)^{*}$ & 0.012 \\
Less satisfied & $26(36.6 \%)$ & $11(15.3 \%)^{*}$ & 0.004 \\
Satisfied & $29(40.9 \%)$ & $44(61.1 \%)^{*}$ & 0.019 \\
Very satisfied & $2(2.8 \%)$ & $13(18.1 \%)^{*}$ & 0.005 \\
\hline
\end{tabular}

Values are numbers (\%).

*Statistically significant $(P<0.05)$

group required less rescue analgesia within $48 \mathrm{~h}$ postoperatively compared with the $C$ group $(P<0.05$, Table 3$)$. In the $\mathrm{D}$ group $(P<0.05$, Table 3$)$, the amounts of the cumulative boluses, actual PCA boluses, and unsuccessful boluses within $48 \mathrm{~h}$ were smaller than those in the $\mathrm{C}$ group.

Compared with the $C$ group, the Ramsay score had no significant differences at $6,12,24,36$ and $48 \mathrm{~h}$ postoperatively $(P>0.05$, Table 4$)$, and the VAS scores at rest and while coughing were lower at $6,12,24,36$ and $48 \mathrm{~h}$ postoperatively in the $\mathrm{D}$ group $(P<0.05$, Table 4$)$.

Compared with the $C$ group, the incidence of nausea and vomiting and rescue antiemetics within $48 \mathrm{~h}$ postoperatively were significantly lower in the D group $(p<$ 0.05 , Table 5$)$. We found no respiratory depression during $48 \mathrm{~h}$ after surgery $(P>0.05$, Table 6$)$.

\section{Discussion}

In this randomised controlled study, dexmedetomidine introduced to a sufentanil and dezocine-based PCA drug blend increased female patients' postoperative global satisfaction degree, reduced the severity and frequency of vomiting and nausea and the requirement for rescue analgesia, minimised the consumption of analgesic, and decreased postoperative pain scores without increasing the incidence of clinically relevant hypertension, hypotension, excessive sedation, sinus bradycardia, hypoxaemia or respiratory depression during the first $48 \mathrm{~h}$ after thoracoscopy.

Table 3 Postoperative rescue analgesia and the number of PCA boluses

\begin{tabular}{llll}
\hline Variable & Group C $(\boldsymbol{n}=\mathbf{7 1})$ & Group D $(\boldsymbol{n}=\mathbf{7 2})$ & $\boldsymbol{P}$ values \\
\hline Rescue analgesia & & \\
No & $50(70.4 \%)$ & $66(91.7 \%)^{*}$ & 0.001 \\
Once & $12(16.9 \%)$ & $4(5.6 \%)^{*}$ & 0.036 \\
Twice & $9(12.7 \%)$ & $2(2.7 \%)^{*}$ & 0.031 \\
& & PCA bolus \\
Total & $14.3 \pm 3.3$ & $10.5 \pm 3.9^{*}$ & $<0.001$ \\
Actual & $11.8 \pm 3.2$ & $9.0 \pm 3.5^{*}$ & $<0.001$ \\
Ineffective & $2.5 \pm 1.6$ & $1.5 \pm 0.9^{*}$ & $<0.001$ \\
\hline
\end{tabular}

Values are means \pm SD or numbers (\%)

*Statistically significant $(P<0.05)$
Table 4 VAS and Ramsay scores within 48 h postoperatively

\begin{tabular}{lllll}
\hline Variable & Time & Group C $(\boldsymbol{n}=\mathbf{7 1})$ & Group D $(\boldsymbol{n}=\mathbf{7 2})$ & $\boldsymbol{P}$ values \\
\hline Rest VAS & 6 & $2.0 \pm 0.9$ & $1.6 \pm 0.9^{*}$ & 0.010 \\
& 12 & $2.0 \pm 1.0$ & $1.7 \pm 0.9^{*}$ & 0.025 \\
& 24 & $2.1 \pm 1.2$ & $1.7 \pm 0.9^{*}$ & 0.023 \\
& 36 & $2.0 \pm 1.5$ & $1.5 \pm 1.1^{*}$ & 0.030 \\
Cough VAS & 6 & $3.0 \pm 0.9$ & $1.5 \pm 0.8^{*}$ & 0.005 \\
& 12 & $3.1 \pm 1.2$ & $2.5 \pm 0.6^{*}$ & $<0.001$ \\
& 24 & $3.0 \pm 1.0$ & $2.7 \pm 0.9^{*}$ & $<0.041$ \\
& 36 & $3.0 \pm 1.4$ & $2.5 \pm 1.1^{*}$ & 0.032 \\
& 48 & $3.0 \pm 1.3$ & $2.3 \pm 0.8^{*}$ & $<0.001$ \\
Ramsay & 6 & $2.2 \pm 0.5$ & $2.3 \pm 0.5$ & 0.060 \\
& 12 & $2.0 \pm 0.2$ & $2.1 \pm 0.3$ & 0.124 \\
& 24 & $2.1 \pm 0.4$ & $2.2 \pm 0.4$ & 0.077 \\
& 36 & $2.0 \pm 0.2$ & $2.1 \pm 0.3$ & 0.097 \\
& 48 & $2.0 \pm 0.3$ & $2.1 \pm 0.3$ & 0.058
\end{tabular}

Values are means \pm SD

*Statistically significant $(P<0.05)$

Opioids, such as sufentanil and morphine, are commonly used with postoperative analgesia and various forms of treatment. Nevertheless, opioid-related adverse effects, such as addiction, respiratory depression, diarrhoea, constipation, pruritus and sedation, compel us to seek novel medications that are suitable as postoperative analgesics to minimise the use of opioids and reduce their negative impacts and have suitable postoperative analgesics. Multimodal analgesia of medications has proven successful [15].

Dezocine is a combined agonist and antagonist of combined opioid receptors, and an increasing amount of research has demonstrated that dezocine use with opioids may decrease opioid intake and the adverse effects correlated with opioids. For instance, Wu et al [7] reported that low dezocine levels could improve postoperative analgesia, nausea and pruritus following thoracotomy. Furthermore, Yu et al [16] showed that dezocine provides a substantial postoperative antihyperalgesic and analgesic impact for up to $48 \mathrm{~h}$ on patients receiving elective open gastrectomy. Dexmedetomidine is an agonist of the highly selective receptor $\alpha_{2}$. Dexmedetomidine is quite appropriate for use as a part of multimodal analgesia because of its analgesic, sedative, hypnotic, and anti-sympathetic effects. Patient-controlled analgesia paired with dexmedetomidine is used to reduce the side effects associated with opioids $[17,18]$.

Patients experience serious pain after thoracoscopic surgery. Effective postoperative analgesia can reduce pain scores, the PCA bolus, and the need for rescue analgesia and increase the overall level of comfort of from 
Table 5 Incidence of postoperative nausea and vomiting and rescue antiemetics within $48 \mathrm{~h}$ after surgery

\begin{tabular}{llll}
\hline Variable & Group C $(\boldsymbol{n}=\mathbf{7 1})$ & Group D $(\boldsymbol{n}=\mathbf{7 2})$ & \multicolumn{1}{c}{ values } \\
\hline Without nausea and vomiting & $28(39.4 \%)$ & $55(76.4 \%)^{*}$ & 0.001 \\
Nausea without vomiting & $21(29.6 \%)$ & $10(13.9 \%)^{*}$ & 0.026 \\
Vomiting $\leq 2$ times & $10(14.1 \%)$ & $3(4.1 \%)^{*}$ & 0.046 \\
Vomiting $>2$ times & $12(16.9 \%)$ & $4(5.6 \%)^{*}$ & 0.036 \\
Rescue antiemetics & $16(22.5 \%)$ & $7(9.7 \%)^{*}$ & 0.043 \\
\hline
\end{tabular}

Values are numbers (\%).

*Statistically significant $(P<0.05)$

analgesic in female patients in the $48 \mathrm{~h}$ after surgery. Such findings showed that introducing dexmedetomidine to sufentanil and PCA based on dezocine could improve the analgesic effects, providing female patients with a better analgesic experience.

PONV is undeniably quite stressful, and even a slight episode will dramatically decrease the degree of patient satisfaction, postpone hospital discharge and increase the utilisation of medical services, particularly for highrisk female patients [19]. This research found that PONV occurrence could be decreased by the addition of dexmedetomidine to sufentanil and dezocine-based PCA. Previous research has indicated that perioperative use of dexmedetomidine could minimise the occurrence of nausea and vomiting [20, 21]. This anti-nausea property may be explained by the direct anti-nausea and anti-vomiting functions of $\alpha_{2}$ receptor agonists. Furthermore, PONV may be decreased by the anti-sympathetic qualities of dexmedetomidine.

The research presented herein revealed no substantial difference in the degree of sedation between the two groups. Dexmedetomidine has sedative qualities and acts on the subcortical system to generate sedation and enhance the quality of postoperative sleep [22-24]. Hence, dexmedetomidine is known to offer sedation without a respiratory disturbance, and the Ramsay sedation scores (RSS) did not indicate unnecessary sedation either.

Table 6 Adverse effects of postoperative analgesia

\begin{tabular}{llll}
\hline Variable & Group C $(\boldsymbol{n}=\mathbf{7 1})$ & Group D $(\boldsymbol{n}=\mathbf{7 2})$ & $\boldsymbol{P}$ values \\
\hline Pruritus & $5(7.0 \%)$ & $4(5.6 \%)$ & 0.745 \\
Hypertension & $3(4.2 \%)$ & $5(6.9 \%)$ & 0.719 \\
Hypotension & $1(1.4 \%)$ & $2(2.8 \%)$ & 1.000 \\
Sinus bradycardia & $1(1.4 \%)$ & $3(4.2 \%)$ & 0.620 \\
Excessive sedation & $3(4.2 \%)$ & $5(6.9 \%)$ & 0.719 \\
Hypoxaemia & $2(2.8 \%)$ & $1(1.4 \%)$ & 0.620 \\
Atrial fibrillation & 0 & 0 & - \\
Respiratory depression & 0 & 0 & - \\
\hline
\end{tabular}

Values are numbers (\%)

*Statistically significant $(P<0.05)$. hypertension (MAP > $90 \mathrm{mmHg}$ );

hypotension (MAP $<60 \mathrm{mmHg}$ ); sinus bradycardia (HR $<60$ beats $/ \mathrm{min}$ ); excessive sedation (RSS $\geq 3$ ); hypoxaemia $(\mathrm{SpO} 2<93 \%)$; respiratory depression (respiratory rate $<8 \mathrm{bpm}$ )
Dexmedetomidine sedation is close to normal sleep, suggesting that the formulation of $0.06 \mu \mathrm{g} / \mathrm{kg} / \mathrm{h}$ dexmedetomidine used in our research procedure did not produce severe sedation of therapeutic importance but may have improved the level of satisfaction of the female patients.

In this clinical trial study, there were some limitations. Firstly, we assessed the degree of satisfaction using the patients' rating on a scale asked by an examiner; this method was subjective. Secondly, because of the time constraints, the sample size was not large enough. Furthermore, this is only a single center study; and there is a need for a multi-center study with a large sample size. In addition, discrepancies in hospitalisation length and medical billing were not assessed and will be examined in future research. A critical limitation is the exclusion of men which limits the generalization of the study findings. Finally, a long-term analysis on the improvement in degree of satisfaction many months later is needed, as research has demonstrated that there may be a correlation between acute postoperative pain and the likelihood of developing chronic pain [25].

In conclusion, combining dexmedetomidine with a sufentanil and dezocine-based PCA drug mixture could improve female patients satisfaction degree in the first $48 \mathrm{~h}$ of after thoracoscopic surgery, providing good analgesic efficacy, less postoperative nausea and vomiting, and no increase in postoperative adverse events.

\section{Conclusions}

Dexmedetomidine combined with sufentanil and dezocine-based increased female patients' global satisfaction degree after thoracoscopic surgery. This effect could be linked to the improvement in postoperative analgesia and reduction in postoperative nausea and vomiting, and did not increase drug-related adverse effects in female patients.

\footnotetext{
Abbreviations

ASA: American Society of Anesthesiologists; BIS: Bispectral index; OLV: Onelung ventilation; TLV: Two-lung ventilation; DLT: Double-lumen tube; HR: Heart rate; ECG: Electrocardiography; MBP: Mean blood pressure; NIBP: Non-invasive blood pressure; $\mathrm{SpO}_{2}$ : Pulse oxygen saturation; TCI: Target-controlled infusion; Ce: Effect-site concentration; I:E: Inspiration/ expiration; FOB: Fibreoptic bronchoscopy; VATS: Video-assisted thoracoscopic surgery; PEEP: Positive end expiratory pressure; PACU: Post-anaesthetic care
} 
unit; DEX: Dexmedetomidine; SD: Standard deviation; PCIA: Patient-controlled intravenous analgesia; PONV: Postoperative nausea and vomiting; VAS: Visual analogue scale cores; RSS: Ramsay sedation score; ERAS: Enhanced recovery after surgery

\section{Acknowledgements}

The authors appreciate the nurse anaesthetists for their presence and assistance in the surgery room of Shanghai Chest Hospital, Shanghai, China.

\section{Authors' contributions}

QZL collection and assembly of data, manuscript writing and editing. HXY provision of study materials or patients. MYX designed the study and the concepts. JXW prepared the manuscript and acquired the data. All authors have read and approved the final version of the manuscript.

\section{Funding}

This research was funded by the Shanghai Municipal Health and Family Planning Project Commission (201840319) and the National Natural Science Foundation (81671078).

\section{Availability of data and materials}

The authors do not wish to share their data because the patients who participated in this study did not agree to share their individual data.

\section{Declarations}

Ethics approval and consent to participate

Write informed consent was required by the Hospital Review Board.

\section{Consent for publication}

Not applicable.

\section{Competing interests}

The authors declare that they have no competing conflicts of interest.

Received: 31 August 2020 Accepted: 5 April 2021

Published online: 21 April 2021

\section{References}

1. Kehlet $\mathrm{H}$, Holte K. Effect of postoperative analgesia on surgical outcome. $\mathrm{Br}$ J Anaesth. 2001;87(1):62-72. https://doi.org/10.1093/bja/87.1.62.

2. Kehlet $\mathrm{H}$, Jensen TS, Woolf CJ. Persistent postsurgical pain: risk factors and prevention. Lancet. 2006;367(9522):1618-25. https://doi.org/10.1016/S0140 6736(06)68700-X.

3. Gottschalk A, Cohen SP, Yang S, Ochroch EA, Warltier DC. Preventing and treating pain after thoracic surgery. Anesthesiology. 2006;104(3):594-600. https://doi.org/10.1097/00000542-200603000-00027.

4. Grosu I, de Kock M. New concepts in acute pain management: strategies to prevent chronic postsurgical pain, opioid-induced hyperalgesia, and outcome measures. Anesthesiol Clin. 2011;29(2):311-27. https://doi.org/10.1 016/j.anclin.2011.04.001.

5. Kawagoe I, Sumida T. Sexual differences in effects and side effects of epidural morphine for VATS (video-associated thoracic surgery). Masui. 2007; 56(6):685-8.

6. Liu R, Huang XP, Yeliseev A, Xi J, Roth BL. Novel molecular targets of dezocine and their clinical implications. Anesthesiology. 2014;120(3):714-23. https://doi.org/10.1097/ALN.0000000000000076.

7. Wu L, Dong YP, Sun L, Sun L. Low concentration of dezocine in combination with morphine enhance the postoperative analgesia for thoracotomy. J Cardiothorac Vasc Anesth. 2015;29(4):950-4. https://doi.org/1 0.1053/j.jvca.2014.08.012.

8. Peng K, Zhang J, Meng XW, Liu HY, Ji FH. Optimization of postoperative intravenous patient-controlled analgesia with opioid-dexmedetomidine combinations: an updated meta-analysis with trial sequential analysis of randomized controlled trials. Pain Physician. 2017;20(7):569-96.

9. Peng K, Liu HY, Wu SR, Cheng H, Ji FH. Effects of combining dexmedetomidine and opioids for postoperative intravenous patientcontrolled analgesia: a systematic review and meta-analysis. Clin J Pain. 2015;31(12):1097-104. https://doi.org/10.1097/AJP.0000000000000219.

10. Nie Y, Liu Y, Luo Q, Huang S. Effect of dexmedetomidine combined with sufentanil for post-caesarean section intravenous analgesia: a randomised, placebo-controlled study. Eur J Anaesthesiol. 2014;31(4):197-203. https://doi. org/10.1097/EJA.0000000000000011.

11. Ren C, Zhang X, Liu Z, Li C, Zhang Z, Qi F. Effect of intraoperative and postoperative infusion of dexmedetomidine on the quality of postoperative analgesia in highly nicotine-dependent patients after thoracic surgery: a consort-prospective, randomized, controlled trial. Medicine (Baltimore). 2015; 94(32):e1329. https://doi.org/10.1097/MD.0000000000001329.

12. Nie $Y, T u$ W, Shen $X, Y u$ W, Yu Y, Song $X$, et al. Dexmedetomidine added to sufentanil patient-controlled intravenous analgesia relieves the postoperative pain after cesarean delivery: a prospective randomized controlled multicenter study. Sci Rep. 2018:8(1):9952. https://doi.org/10.103 8/s41598-018-27619-3.

13. Wang $X$, Wang $K$, Wang $B$, Jiang $T$, Xu Z, Wang F, et al. Effect of oxycodone combined with dexmedetomidine for intravenous patient-controlled analgesia after video-assisted thoracoscopic lobectomy. J Cardiothorac Vasc Anesth. 2016;30(4):1015-21. https://doi.org/10.1053/j.jvca.2016.03.127.

14. Dong CS, Zhang J, Lu Q, Sun P, Yu JM, Wu C, et al. Effect of dexmedetomidine combined with sufentanil for post- thoracotomy intravenous analgesia:a randomized, controlled clinical study. BMC Anesthesiol. 2017;17(1):33. https://doi.org/10.1186/s12871-017-0324-4.

15. Gritsenko K, Khelemsky Y, Kaye AD, Vadivelu N, Urman RD. Multimodal therapy in perioperative analgesia. Best Pract Res Clin Anaesthesiol. 2014; 28(1):59-79. https://doi.org/10.1016/j.bpa.2014.03.001.

16. Yu F, Zhou J, Xia S, et al. Dezocine prevents postoperative hyperalgesia in patients undergoing open abdominal surgery. Evid Based Complement Alternat Med. 2015:2015:946194.

17. Kweon DE, Koo Y, Lee S, Chung K, Ahn S, Park C. Postoperative infusion of a low dose of dexmedetomidine reduces intravenous consumption of sufentanil in patient-controlled analgesia. Korean J Anesthesiol. 2018;71(3): 226-31. https://doi.org/10.4097/kja.d.18.27056.

18. Lu J, Chen G, Zhou H, Zhou Q, Zhu Z, Wu C. Effect of parecoxib sodium pretreatment combined with dexmedetomidine on early postoperative cognitive dysfunction in elderly patients after shoulder arthroscopy: a randomized double blinded controlled trial. J Clin Anesth. 2017;41:30-4. https://doi.org/10.1016/j.jclinane.2017.06.004.

19. Apfel CC, Läärä E, Koivuranta M, Greim CA, Roewer N. A simplified risk score for predicting postoperative nausea and vomiting: conclusions from crossvalidations between two centers. Anesthesiology. 1999;91(3):693-700. https://doi.org/10.1097/00000542-199909000-00022.

20. Song Y, Shim JK, Song JW, Kim EK, Kwak YL. Dexmedetomidine added to an opioid-based analgesic regimen for the prevention of postoperative nausea and vomiting in highly susceptible patients: a randomised controlled trial. Eur J Anaesthesiol. 2016;33(2):75-83. https://doi.org/10.1097/EJA. 0000000000000327.

21. Geng ZY, Liu YF, Wang SS, Wang DX. Intra-operative dexmedetomidine reduces early postoperative nausea but not vomiting in adult patients after gynaecological laparoscopic surgery: a randomised controlled trial. Eur Anaesthesiol. 2016;33(10):761-6. https://doi.org/10.1097/EJA. 0000000000000491

22. Chen $Z$, Tang $R$, Zhang $R$, Jiang $Y$, Liu Y. Effects of dexmedetomidine administered for postoperative analgesia on sleep quality in patients undergoing abdominal hysterectomy. J Clin Anesth. 2017;36:118-22. https:// doi.org/10.1016/j.jclinane.2016.10.022.

23. Nelson LE, Lu J, Guo T, Saper CB, Franks NP, Maze M. The alpha2adrenoceptor agonist dexmedetomidine converges on an endogenous sleep-promoting pathway to exert its sedative effects. Anesthesiology. 2003; 98(2):428-36. https://doi.org/10.1097/00000542-200302000-00024

24. Hall JE, Uhrich TD, Barney JA, Arain SR, Ebert TJ. Sedative, amnestic, and analgesic properties of small-dose dexmedetomidine infusions. Anesth Analg. 2000;90(3):699-705. https://doi.org/10.1097/00000539-20000300000035 .

25. Hazelrigg SR, Cetindag IB, Fullerton J. Acute and chronic pain syndromes after thoracic surgery. Surg Clin North Am. 2002;82(4):849-65. https://doi. org/10.1016/S0039-6109(02)00031-2.

\section{Publisher's Note}

Springer Nature remains neutral with regard to jurisdictional claims in published maps and institutional affiliations. 